\title{
The role of hematopoietic stem cell transplantation for type 1 diabetes mellitus
}

\section{o papel do transplante de célula-tronco hematopoética no diabetes mellitus tipo1}

\author{
Júlio C. Voltarelli \\ Carlos Eduardo B. Couri \\ Maria Carolina Rodrigues \\ Ana Beatriz P. L. Stracieri \\ Daniela A. Moraes \\ Fabiano Pieroni \\ George Navarro \\ Maria Isabel A. Madeira \\ Belinda P. Simões
}

\begin{abstract}
In this review, we present 1) scientific basis for the use of high dose immunosuppression followed by autologous peripheral blood hematopoietic stem cell transplantation for newly diagnosed type 1 diabetes mellitus, 2) an update of clinical and laboratory outcomes in 21 patients transplanted at the University Hospital of the Ribeirão Preto Medical School, University of São Paulo, Brazil, including 6 relapses in patients without previous ketoacidosis and 3) a discussion of future prospectives of cellular therapy for type 1 diabetes mellitus. Rev. bras. hematol. hemoter. 2008; 30(Supl. 2):55-59.
\end{abstract}

Key words: Diabetes mellitus; cellular therapy; hematopoietic stem cell transplantation.

\section{Introduction}

Based on animal models of autoimmune diseases successfully treated with high-dose immunosuppression plus hematopoietic stem cells (autologous or allogeneic) and on remission of coincidental autoimmune diseases (AID) in patients treated for hematological disorders (reviewed in $^{1-4}$ ) in 1996 the first patients with isolated AID were treated with hematopoietic stem cell transplantation (HSCT). Since then, more than 1,000 patients with severe and refractory AID have been treated, ${ }^{5}$ most with autologous HSCT, because of the lower risk of complications compared to allogeneic HSCT. Between one to two-thirds of patients experienced sustained remission of their disease. Relapses and mortality rates varied with type and status of the disease and with the intensity of immunosuppression employed pretransplant (myeloablative versus nonmyeloablative conditioning regimens).

Few mechanistic studies performed after HSCT for AID suggest that the regenerated immune system is more tolerant with a regulatory phenotype, marked by increased numbers of naïve and regulatory $\mathrm{T}$ cells and more diverse $\mathrm{T}$ cell receptor repertoire diversity.

\section{Evidence for using hsct in human type 1 diabetes mellitus}

After more than ten years of clinical use of HSCT for severe and refractory AID, the evidence that this approach could be beneficial for human type 1 diabetes mellitus (T1DM) is derived from experimental studies with animal models of T1DM and from clinical studies using immunosuppression for early onset DM-1 or in hematopoietic stem cell transplantation for hematological diseases where donor or recipient had T1DM (Table 1).

\section{Experimental studies}

There are two types of experimental models of autoimmune diseases, one genetically determined, like the nonobese diabetic (NOD) and the NZB/W mice, in which AID develops spontaneously in most animals, and another one in, like adjuvant arthritis and experimental autoimmune encephalomyelitis, in which AID is induced by immunization with the relevant antigen plus Freund adjuvant. The latter model is considered more relevant to human AID, but no such model exists for type 1 DM.

In NOD mice, development of clinical overt T1DM is easily prevented by allogeneic stem cell transplantation, but

Department of Clinical Medicine, Ribeirão Preto School of Medicine, University of São Paulo, SP, Brazil.

Correspondence: Júlio C. Voltarelli

Blood Center (Hemocenter), Campus USP (University of São Paulo)

14051-140 - Ribeirão Preto - SP - Brazil

Phone: 55-16-2101-9369

E-mail: jcvoltar@fmrp.usp.br 
Table 1. Scientific evidence for the possible benefit of high dose immunosuppression followed by hematopoietic stem cell infusion in newly diagnosed type 1 diabetes mellitus

\begin{tabular}{lr}
\hline Evidence & Ref \\
\hline $\begin{array}{l}\text { Beneficial effects of HSCT for human severe } \\
\text { autoimmune diseases }\end{array}$ & $2-5$ \\
$\begin{array}{l}\text { Results of HSCT in experimental models of type 1 DM } \\
\text { Beneficial effects of immunosuppression in }\end{array}$ & $1,8-9$ \\
human type 1 DM & $10-14$ \\
$\begin{array}{l}\text { Lack of benefit of HSCT in long term T1DM } \\
\text { Transfer of DM1 during HSCT in humans }\end{array}$ & 15 \\
\hline
\end{tabular}

not by autologous HSCT, result that can be anticipated by the genetic nature of the disease in this model. ${ }^{8}$ On the other hand, overt T1DM in NOD mice cannot be reversed by allogeneic HSCT alone, requiring a source of pancreatic betacells. ${ }^{9}$ These findings indicate that allogeneic HSC can reinduce tolerance to pancreatic beta-cells in DM1 but cannot restore the pool of those cells once it was destroyed by the autoimmune process.

\section{Immunosuppression for early onset disease}

Immune-mediated islet cell destruction is not complete until sometime after onset of T1DM. This has lead, beginning in the $1980 \mathrm{~s}$, to immunosuppression trials for new onset T1DM (reviewed in ${ }^{10,11}$ ). Early diagnosed type I diabetes patients were treated with prednisone, cyclosporine and/or azathioprine. Several trials including French, CanadianEuropean, Australian, and American indicated that cyclosporine and/or azathioprine preserved insulin secretion and/or increased the duration of insulin independence. The best results seemed to occur for patients with 8 weeks of T1DM onset. Despite preserving insulin secretion, long term immunosuppression was impractical due to chronic side effects. These studies indicate that islet cells persist, at least for a short time interval of weeks to months after T1DM onset. Measurements of C-peptide, a marker for endogenous insulin, indicate persistence of islet cells with low normal C-peptide levels for 1 year after T1DM onset.

The most encouraging results have been observed after short-term courses of engineered anti-CD3 monoclonal antibodies. These studies were pioneered by Eisenbarth et $a l^{12}$ who induced transient remission (up to 8 months) in a small group of T1DM treated with prednisone plus antithymocyte globulin (ATGAM). In one recent study, 12 patients treated with the antibody showed better beta-cell function and lower insulin dosage after one-year, compared to the placebo group. ${ }^{13}$

In a subsequent study with larger number of patients and extended follow-up, the metabolic (increase in C-peptide levels) and clinical (decrease in insulin usage) benefits was maintained up to 2 years after diagnosis. ${ }^{14}$ However, in neither study a significant number of patients became insulin free after immunointervention. In those studies, the long-term increase of regulatory $\mathrm{T}$ cells (Tregs) could be implicated in prolonged protection (18-24 months) of pancreatic beta-cells from autoimmune aggression.

Currently, several trials of immunosuppression for early onset T1DM are being conducted, using polyclonal ATG, anti-IL2 receptor monoclonal antibody, mycophenolate mofetil, sirolimus, tacrolimus, anti-CD52 (Campath-1H) or antiCD20 (Rituximab) monoclonal antibodies. ${ }^{10}$

\section{HSCT for hematological diseases where donor or recipient had type $1 \mathrm{DM}$}

Only one study, from Seattle, investigated the effect of high dose immunosuppression and HSCT on the metabolic control of three patients with T1DM transplanted for hematological diseases (Fanconi anemia, T cell acute lymphoblastic leukemia or acute myelomonocytic leukemia). ${ }^{15}$ Two patients received HLA-identical bone marrow transplantation from family relatives (mother or sister) and one patient received syngeneic HSCT from an identical twin. In this study, the long term disease process ( 3 to 7 years) was not changed by HSCT, as evaluated by continuous use of insulin after transplantation. On the other hand, there are few reports of transference of T1DM from donor to recipient of allogeneic HSCT for hematological diseases, ${ }^{16}$ indicating that HSC may carry disease predisposition in the allogeneic transplantation setting.

Based on the above discussed evidence, HSCT for early onset T1DM was proposed in review articles in the literature in $2001^{17}$ and $2002^{18}$ and a cooperative protocol between Northwestern University in Chicago, USA (Richard Burt) and University of São Paulo in Ribeirão Preto, Brazil (Júlio Voltarelli and others) started in Brazil in the end of 2003 after approval by local and national Institutional Review Boards.

\section{Results of autologous HSCT for newly diagnosed type 1 diabetes mellitus}

Since 2003, our research group in Brazil is conducting an original study of nonmyeloablative autologous hematopoietic stem cell transplantation (AHSCT) in patients with newly diagnosed T1DM. The objective of the treatment was to stop autoimmune destruction of $\beta$ cells with highdose immunosuppressive drugs (cyclophosphamide and rabbit antithymocyte globulin) and to "reset" the deleterious immunologic system with a reconstituted one originated from autologous hematopoietic stem cells. ${ }^{19}$ The rational is to preserve residual $\beta$ cell mass and facilitate endogenous mechanisms of $\beta$ cell regeneration. Hematopoietic stem cells probably do not have the capacity to differentiate into large numbers $\beta$ cells, therefore these cells are used solely to regenerate new immune system without autoreactive memory cells against pancreatic antigens (see below). The exact 
mechanism of action operating in this treatment is still unclear. However, it has been suggested that AHSCT may shift the balance from destructive immunity to immune tolerance through clonal exhaustion, regulatory cells, cytokine alterations and changes in T- or B-cell repertoires. ${ }^{1,2}$

The procedure of AHSCT comprises several steps from patient selection through long-term follow-up. Most patients interested in the study were excluded for not fulfilling protocol criteria, especially the short time period (6 weeks) from diagnosis, occasionally positivity for anti-GAD antibodies or fully understanding and complying with the study protocol. Apart from the diabetic status, all treated patients were in good health status before transplantation, which explains in part the low frequency and severity of adverse effects (see below). This is also explained by the rapid engraftment of neutrophils (mean of 9 days) and platelets (mean of 11.4 days). ${ }^{19}$

The first patient enrolled in December/2003 presented discouraging response. His insulin requirements increased progressively until 12 months following transplantation (when he abandoned follow-up) reaching the dose $250 \%$ higher than his initial requirement. His hemoglobin A1c level was $11.1 \%$ at 12 months and his Cpeptide concentration did not increase. The possible cause for his poor clinical response is the very low $\beta$ cell reserve, predicted by the previous diagnosis of diabetic ketoacidosis, and further jeopardized by the $\beta$ cell apoptotic effect of glucocorticoids used to prevent rabbit antithymocyte globulin reactions. Considering these possibilities, we decided not use glucocorticoids in the conditioning regimen in the following patients and did not include those with previous diabetic ketoacidosis.

At April 2008, after a median follow-up of 28 months (range between 1 to 49 months) all but one of the subsequent 19 patients became insulin-free, most of them shortly after starting high dose immunosuppression, even before stem cell infusion. Six out of 19 patients resumed insulin use after transient periods free from insulin ranging from 7 to 48 months (mean 22.4 months) (Figure 1). Five of them are receiving $30-50 \%$ of insulin doses compared to the doses used before transplantation and one patient is using higher doses than pretransplantation. Two of these patients resumed insulin use after an upper respiratory tract infection. The other 13 patients are continuously insulin-free since insulin suspension: 3 patients for at least 3 years, 4 patients for at least 2 years, 3 patients for at least 1 year and 4 patients for at least 3 months
Patients transiently free from insulin along the follow-up

Temporal evolution of insulin use

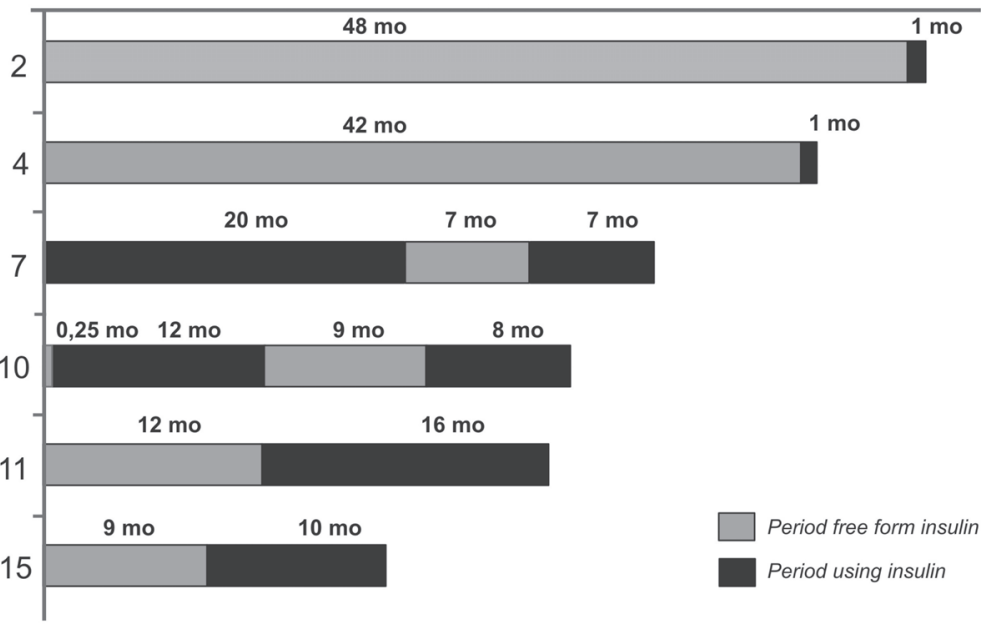

All patients without previous DKA

Total: 6 patients

Figure 1. Insulin usage after autologous hematopoietic stem cell transplantation in 6 type $1 \mathrm{DM}$ patients with transient response. No patient had diabetic ketoacidosis or used corticosteroids during the transplantation procedure.

Patients continuously insulin free since AHSCT

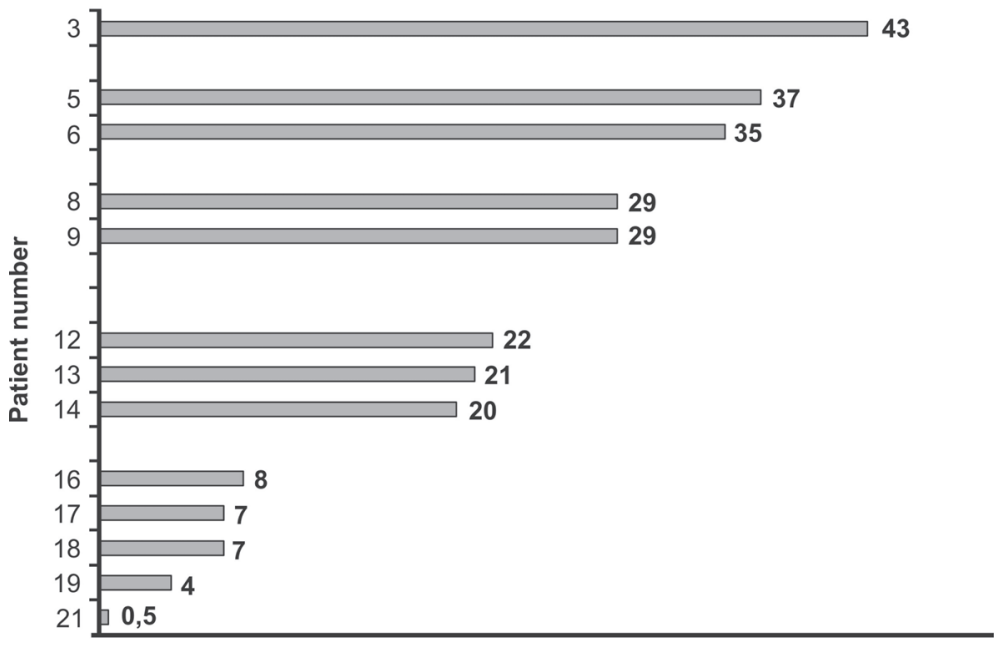

Time free from insulin (months)

Total: 13 patients

Figure 2. Insulin usage after autologous hematopoietic stem cell transplantation in 13 type $1 \mathrm{DM}$ patients with sustained response. No patient had diabetic ketoacidosis or used corticosteroids during the transplantation procedure

(Figure 2). The 20th patient did not present any period free from insulin, but this patient received steroids $(300 \mathrm{mg}$ hydrocortisone) along with stem cell infusion to prevent reactions to DMSO.

There was a statistically significant reduction of mean hemoglobin A1c concentrations after transplantation. All but 
2 patients (the $1^{\text {st }}$ and the $11^{\text {th }}$ ) presented all measurements below 7\% (upper limit of good glucose control) during followup. As noted above, soon after inclusion, the $1^{\text {st }}$ patient did not achieve good glucose control. The $11^{\text {th }}$ patient presented A1c levels $<7 \%$ until 12 months after transplantation when insulin use was restarted and hemoglobin A1c began to increase.

Regarding the time course of $\beta$ cell function, of the first 14 patients who had C-peptide levels partially analyzed the majority $(n=11)$ presented increased values in comparison with pretreatment levels, indicating preservation and even improvement of $\beta$ cell function. Analyzing Cpeptide levels during a stimulus with mixed meal tolerance test, there was a statistically significant increase in mean area under the curve 6 months after transplantation and this increase was maintained until 24 months after stem cell transplantation. ${ }^{19}$

In face of the good metabolic results presented, the adverse effects were acceptable. With respect to acute complications, most patients had febrile neutropenia, nausea, vomiting and alopecia due to the immunosuppressive agents used in the mobilization and conditioning phases of the protocol. Bilateral pneumonia of unidentified etiology that required supplementary oxygen therapy and responded completely to broad-spectrum antibiotics occurred in patients \#2 and \#21 and they were the only severe acute complications of the transplantation procedure. During long-term followup, patient 2 presented Graves disease identified 3.5 years after transplantation, patient 3 developed autoimmune hypothyroidism and transient renal dysfunction associated with rhabdomyolysis, a complication that was successfully treated with levothyroxine. Patient \#10 presented mild transient hypergonadotropic hypogonadism 12 months after transplantation. These late onset endocrine dysfunctions presented by these 3 patients can be related to the transplant procedure itself or to an autoimmune polyendocrine syndrome frequently associated with T1DM. There was no mortality.

In July 2007 we initiated a similar study of nomyeloablative autologous hematopoietic stem cell transplantation in newly diagnosed individuals with T1DM who presented previous diabetic ketoacidosis. By January 2008 only one patient had been enrolled in the study and insulin independence was not achieved, but insulin doses decreased by less than $40 \%$ of the initial requirements.

We are currently performing exhaustive studies of immunoreconstitution (phenotypic and functional) in the transplanted patients to unravel the mechanisms by which AHSCT produces clinical benefit in type 1 diabetic patients. Preliminary results show that after transplantation, there is an increase in the numbers of regulatory $\mathrm{CD} 4+\mathrm{CD} 25+\mathrm{Foxp} 3+$ $\mathrm{T}$ cells and Th2 cytokines-producing cells, compared to the pre-transplant status. In addition, we found after AHSCT profound qualitative and quantitative changes in TCR repertoire, as well as alterations in the expression of pro- and anti-apoptotic genes ${ }^{20,21}$ Anti-GAD autoantibodies decreased in most patients but did not correlate with clinical response. Our immune reconstitution results are underway and preliminary results resemble those observed in other autoimmune diseases after AHSCT. ${ }^{6,7}$ The results support the suggested hypothesis that a new and more tolerant immune system is generated after the treatment, explaining the reduction of autoimmune destruction and clinical improvement (Mechanism \#2, Table 2). However, in the presence of anti-GAD autoantibodies and in the absence of specific immunologic reactivity tests to beta cell antigens, we cannot be sure that our treatment blocks autoimmune attack to endocrine pancreas more efficiently and for longer time than other immunosuppressive interventions, particularly anti-T cell therapies.

\section{Table 2. Possible mechanisms of action of autologous hematopoietic stem cell transplantation for type 1 diabetes mellitus} 1. Ablation of autoreactive immune system by high dose
immunosuppression

2. Regeneration of a naïve immune system from autologous hematopoietic stem cells after lymphoablation by high dose immunosuppression

3. Regeneration of pancreatic beta-cells from autologous bone marrow stem cells mobilized to the peripheral blood

\section{Conclusions and prospectives}

Our preliminary study of autologous HSCT in a subset of non-ketoacidotic newly diagnosed type $1 \mathrm{DM}$ patients yield unexpected positive results: 19/20 patients could stop insulin use after initiation of high dose immunosuppression and 16 patients maintained this status after a median followup of almost two years (maximum of 4 years). Six patients relapsed after stopping insulin use and one patient who received steroids during conditioning never discontinued insulin. Longer follow-up and controlled studies are certainly needed to evaluate the full potential of the procedure in the reversion of type $1 \mathrm{DM}$.

The underlying mechanism of action of the various components of the AHSCT (cyclophosphamide, ATG and stem cells) cannot be studied by direct methods in humans, but our immune reconstitution study which is currently underway and similar studies in other AIDs suggest that the immune system is reset towards a tolerant phenotype by increased regulatory $\mathrm{T}$ cell numbers and by regeneration of a different and more diverse TCR repertoire. We hypothesize that the combination of high dose immunosuppression and hematopoietic stem cell infusion act synergistically to downregulate the autoreactive cells, to renew the immune system and to improve the immune regulatory networks. 
While our approach provides the proof of principle that high dose immunosuppression coupled with autologous hematopoietic stem cell boosting can revert clinical type $1 \mathrm{DM}$ in humans, it will hardly solve the problem of the disease. Firstly, only a small subset of patients were successfully treated with AHSCT, millions of patients with long standing type 1 DM need another source of stem cells to regenerate pancreatic beta-cells and other damaged tissues. Secondly, AHSCT is an expensive, cumbersome and complex procedure performed in specialized bone marrow transplantation facilities and has the potential of life threatening short and long term complications. In the future, more simple approaches such as chemical, biological or cellular immunoregulatory interventions may accomplish the same therapeutic goal and may be applied to millions of type 1 diabetic patients who need a definitive treatment. In the meanwhile, AHSCT remains the only treatment to reverse the disease in humans and has to be tested in other groups of patients (with previous ketoacidosis, with longer duration of the disease and in young children).

\section{Resumo}

Nesta revisão, são apresentadas: 1) as bases cientificas para o uso de imunossupressão em alta dose seguida de transplante autólogo de células-tronco hematopoéticas do sangue periférico no diabete melito do tipo 1 recém-diagnosticado; 2) uma atualização da evolução clínica e laboratorial de 21 pacientes transplantados no Hospital das Clínicas da Faculdade de Medicina de Ribeirão Preto, da Universidade de São Paulo, Brasil, incluindo recaídas em seis pacientes transplantados sem cetoacidose prévia; e 3) uma discussão das perspectivas futuras de terapia celular no diabete melito do tipo 1. Rev. bras. hematol. hemoter. 2008; 30(Supl. 2):55-59

Palavras-chave: Diabete melito; terapia celular; transplante de células-tronco hematopoéticas.

\section{References}

1. Sykes M, Nikolic B. Treatment of severe autoimmune disease by stem-cell transplantation. Nature. 2005;435(7042):620-7.

2. Marmont AM. New horizons in the treatment of autoimmune diseases: mmunomodulation and stem cell transplantation. Annu Rev Med. 2000;51:115-34

3. Moore J, Tyndall A, Brooks P. Stem cells in the aetiopathogenesis and therapy of rheumatic diseases. Best Pract Res Clin Rheumatol. 2001;15(5):711-26.

4. Burt RK, Loh Y, Pearce W, Beohar N, Barr WG, Craig R et al. Clinical applications of blood-derived and marrow-derived stem cells for nonmalignant diseases. JAMA. 2008;299(8):925-36.

5. Passweg J, Tyndall A. Autologous stem cell transplantation in autoimmune diseases. Semin Hematol. 2007;44(4):278-85.

6. Muraro PA, Douek DC, Packer A, Chung K, Guenaga FJ, CassianiIngoni $\mathrm{R}$ et al. Thymic output generates a new and diverse TCR repertoire after autologous stem cell transplantation in multiple sclerosis patients. J Exp Med. 2005;201(5):805-16.

7. de Kleer I, Vastert B, Klein M, Teklenburg G, Arkesteijn G, Yung GP et al. Autologous stem cell transplantation for autoimmunity induces immunologic self-tolerance by reprogramming autoreactive
$\mathrm{T}$ cells and restoring the $\mathrm{CD} 4+\mathrm{CD} 25+$ immune regulatory network. Blood. 2006;107(4):1696-702.

8. Atkinson MA, Leiter EH. The NOD mouse model of type 1 diabetes: as good as it gets? Nat Med. 1999;5(6):601-4.

9. Kang EM, Zickler PP, Burns S, Langemeijer SM, Brenner S, Phang OA et al. Hematopoietic stem cell transplantation prevents diabetes in NOD mice but does not contribute to significant islet regeneration once disease is established. Exp Hematol. 2005;33(6): 699-705.

10. Staeva-Vieira T, Peakman M, von Herrath M. Translational minireview series on type 1 diabetes: Immune-based therapeutic approaches for type 1 diabetes. Clin Exp Immunol. 2007;148(1):17-31.

11. Couri CEB, Foss-Freitas MS, Foss MC, Voltarelli JC. Beta-cell regeneration to treat type 1 diabetes mellitus. Expert Review of Endocrinology \& Metabolism 2008;3:51-60.

12. Eisenbarth GS, Srikanta S, Jackson R, Rabinowe S, Dolinar R, Aoki T, et al. Anti-tymocyte globulin and prednisone immunotherapy of recent onset type 1 diabetes mellitus. Diabetes Res. 1985;2(6):271-6.

13. Keymeulen B, Vandemeulebroucke E, Ziegler AG, Mathieu C, Kaufman $\mathrm{L}$, Hale $\mathrm{G}$ et al. Insulin needs after CD3 antibody-therapy in newonset type 1 diabetes. N Engl J Med. 2005;352 (25):2598-608.

14. Herold KC, Gitelman SE, Masharani U, Hagopian W, Bisikirska B, Donaldson D et al. A single course of anti-CD3 monoclonal antibody hOKT3gamma 1 (Ala-Ala) results in improvement in Cpeptide resaponses and clinical parameters for at least 2 years after onset of type 1 diabetes. Diabetes. 2005;54(6):1763-9.

15. Nelson JL, Torrez R, Louie FM, Choe OS, Storb R, Sullivan KM. Pre-existing autoimmune disease in patients with longterm survival after allogeneic bone marrow transplantation. J Rheumatol Suppl. 1997;48:23-9

16. Lampeter EF, McCann SR, Kolb H. Transfer of insulin-dependent diabetes by bone marrow transplantation. Lancet. 1998;351 (9102):568-9.

17. Domenick MA \& Ildstad S. Impact of bone marrow transplantation on type I diabetes. World J Surg. 2001;25(4):474-80.

18. Burt RK, Oyama Y, Traynor A, Kenyon NS. Hematopoietic stem cell teraphy for type 1 diabetes: induction of tolerance and islet cell neogenesis. Autoimmune Rev. 2002;1(3):133-8.

19. Voltarelli JC, Couri CE, Stracieri AB, Oliveira MC, Moraes DA, Pieroni $\mathrm{F}$ et al. Autologous nonmyeloablative hematopoietic stem cell transplantation in newly diagnosed type 1 diabetes mellitus. JAMA. 2007;297(14):1568-76.

20. Malmegrim KCR, Fae KC, Palma PVB, Morais FR, Silva ACG, Guilherme L, Voltarelli JC. Changes in the TCR repertoire and FoxP3 regulatory gene expression after autologous stem cell transplantation in type 1 diabetes mellitus and multiple sclerosis patients. Presented at the 13th International Congress of Imunology, Rio de Janeiro, Brazil, 2007 August 21-25, Abstract P1207.

21. Oliveira GLV, Malmegrim KCR, Silva ACG, Ferreira AF, Gasparotto EPL, Kashima S et al. Downregulated expression of the bcl-xl and mci-1 antiapoptotic genes in type 1 diabetes patients after autologous hematopoietic stem cell transplantation. Presented at the 13th International Congresso f Imunology, Rio de Janeiro, Brazil, 2007 August 21-25, Abstract P1208.

O tema apresentado constou do programa do Encontro AIBE. Avaliadores: Professores Ângelo Maiolino, Cármino Antonio de Souza e Marcio Nucci.

Publicado após concordância do editor.

Conflito de interesse: não declarado.

Recebido: 09/05/2008

Aceito: 20/05/2008 